\title{
La movilidad, un asunto que nos compete a todos
}

Mobility, a matter that concerns us all

\section{Valentina Cárdenas Cadena*}

(C) Recepción: $24 / 10 / 2019$

C Aprobación: 27/11/2019

C Publicación: 19/12/2019

\section{Para citar este artículo:}

D. Cárdenas Cadena, V. (2019). La movilidad, un asunto que nos compete a todos. Indagare, (7), 81-86. https://doi.org/10.35707/indagare/711

* Estudiante del programa de Comunicación Social y Periodismo de la Universidad de Ibagué. ORCID: 0000-0001-85696745. cardenas.valentina0@gmail.com 


\title{
Resumen
}

La movilidad en una ciudad se ha convertido en un tema de agenda pública. Las personas empiezan a preocuparse sobre futuras proyecciones para el mejoramiento de la misma. Por esta razón es que nace en la XI Escuela Internacional de Verano de la Universidad de la Ibagué el curso: "Diseño de calles para ciudades del siglo XXI", que pretende resaltar la movilidad desde una visión inclusiva.

\begin{abstract}
Mobility in a city has become a public agenda issue. People begin to worry about future projections for its improvement. For this reason, the course "Design of streets for cities of the 21 st century" was born at the XI International Summer School of the University deIbagué, which aims to highlight mobility from an inclusive vision.
\end{abstract}

Palabras claves: Movilidad, ingeniería, ciudadanía, calles, vías.

Keywords: Mobility, engineering, citizenship, streets, roads.

En los últimos años, la movilidad se ha convertido en un discurso común y político. Los medios de comunicación desarrollan en sus agendas este tema, y la ciudadanía empieza a comprender la importancia y afectación de proyectos relacionados con la movilidad de la ciudad.

En la XI Escuela Internacional de Verano de la Universidad de la Ibagué, el docente invitado, Edgar Jiménez, junto con el profesor, Juan Guillermo Zuluaga, presentaron el curso: "Diseño de calles para ciudades del siglo XXI", con el que buscaban generar un debate y análisis de las visiones y metodologías tradicionales de la ingeniería de transporte, y de esta forma plantear propuestas alternativas y mejores opciones para transformar las calles existentes de la ciudad de Ibagué, con un enfoque contemporáneo en el que se privilegie a las personas en la jerarquía de la movilidad.

Indagare tuvo la oportunidad de hablar con los docentes sobre este curso y el futuro de la movilidad en la capital del Tolima. Edgar Jiménez es doctor en Sistemas de Transporte del Programa MIT Portugal, con experiencia en consultoría, investigación y docencia en diferentes modos de transporte, en particular transporte urbano y transporte aéreo. Ha trabajado en diseño de políticas públicas, gestión y diseño de proyectos en transporte, movilidad urbana y educación superior. Actualmente se desempeña como profesor de tiempo completo en la Escuela de Aero-espacio, Transporte y Manufactura de la Universidad de CranField, en el Reino Unido. 


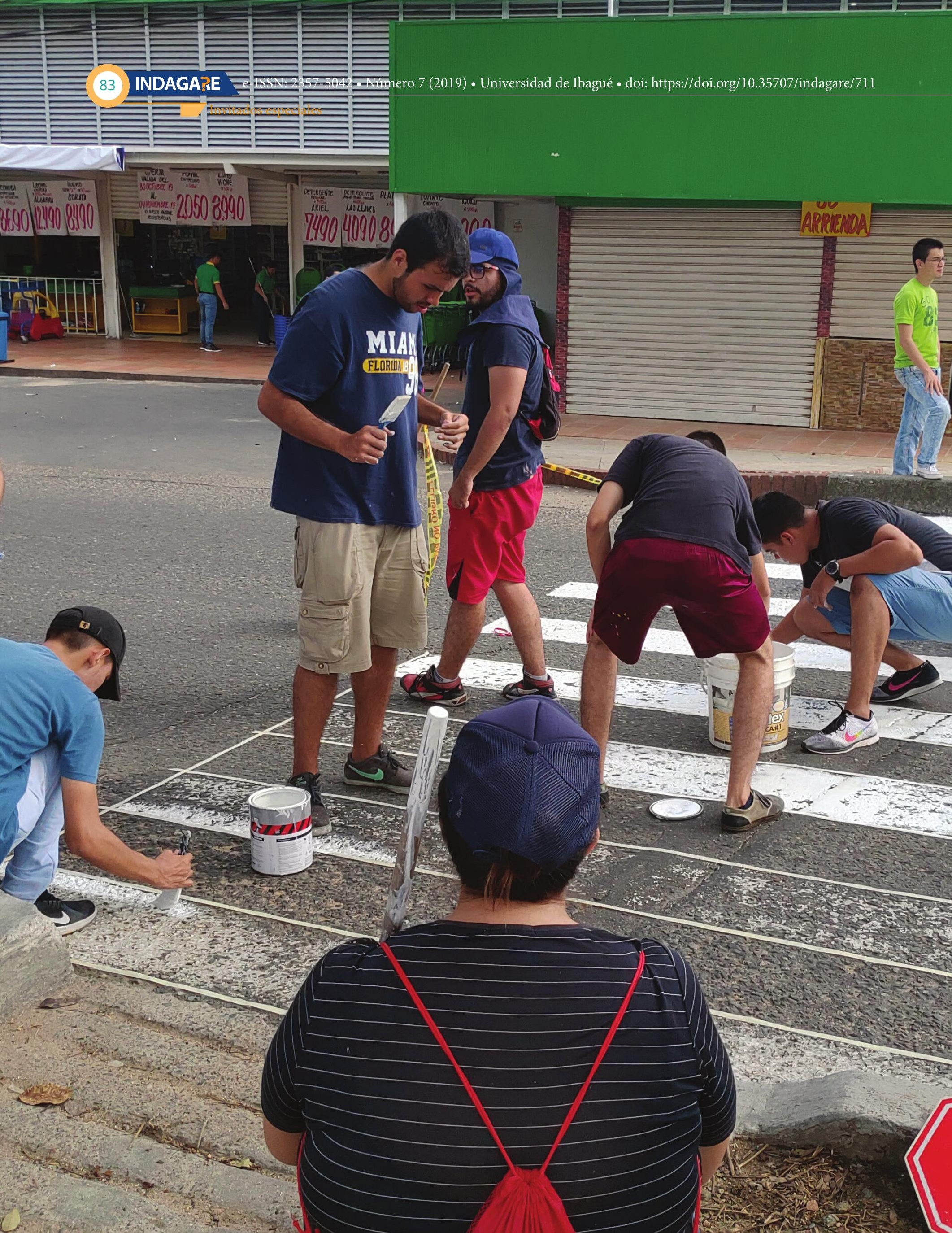


¿Cómo surge la idea de diseño de calles para ciudades del siglo XXI?

Edgar Jiménez: En Ingeniería Civil los estudiantes cursan “Diseño de vías”. Pero en esta se habla normalmente del diseño de carreteras; es decir, el espacio de tránsito de los vehículos en términos interurbanos, para ir de una ciudad a otra. Y aquello que siempre hacíamos en las ciudades, era intentar aplicar los mismos estándares de los contextos interurbano y urbano. Esto generó velocidades muy altas en circulación, más congestión y desorden en las ciudades. Por eso quisimos darle un enfoque específico al diseño de calles urbanas. Hablamos de ciudades del siglo XXI, porque el siglo pasado nos dejó ciudades diseñadas para favorecer más el movimiento de los vehículos. Por ello nos parece normal que los carros - y las motos - tengan prioridad en nuestros espacios urbanos, aceptamos que no haya andenes y estacionamientos en todos lados, pese a que la mayoría de viajes se realizan de otros modos. Para este siglo debemos reorganizar nuestras prioridades. Pensar en ciudades que sean más habitables, que ofrezcan más calidad de vida a sus habitantes y visitantes.

\section{Al tener en cuenta que usted ha salido y reside fuera del país, ¿ cree que esas experiencias} en otros países le aportaron para cambiar la mirada tradicional?

Edgar Jiménez: Siempre que tengo la posibilidad de visitar nuevos lugares, no solamente fuera del país, sino dentro de él, intento tener una visión más observadora de la manera en la que funcionan las cosas. Lo más interesante de todas esas experiencias, es darse cuenta que hay lugares mucho más deseables, sobre todo en algunas ciudades de Europa, donde es más claro el respeto por los peatones, es más fácil andar en bicicleta y el transporte público funciona muy bien.

Muchas veces nos quejamos de Colombia, de Ibagué, y decimos que no podemos cambiar nada porque tenemos una cultura específica, o incluso que no hay cultura. Entonces ese conocimiento de diferentes experiencias en otros contextos, sirve para darse cuenta de que no es difícil realizar transformaciones culturales. De por sí ya sucedió una transformación cultural y fue la de aceptar los carros en las ciudades, porque eso es algo nuevo. En Ibagué lo vivimos desde hace aproximadamente 20 o 25 años. Así que las transformaciones culturales se pueden promover si cambiamos primero las concepciones que tenemos como diseñadores.

La coordinación del curso también estuvo a cargo del profesor Juan Guillermo Zuluaga, Ingeniero Civil de la Universidad de Ibagué. Estudiante de la especialización en Vías y Transporte de la Universidad Nacional de Colombia, sede Manizales, y docente de la Universidad de Ibagué. El ingeniero Zuluaga realiza investigaciones en el ámbito de la 


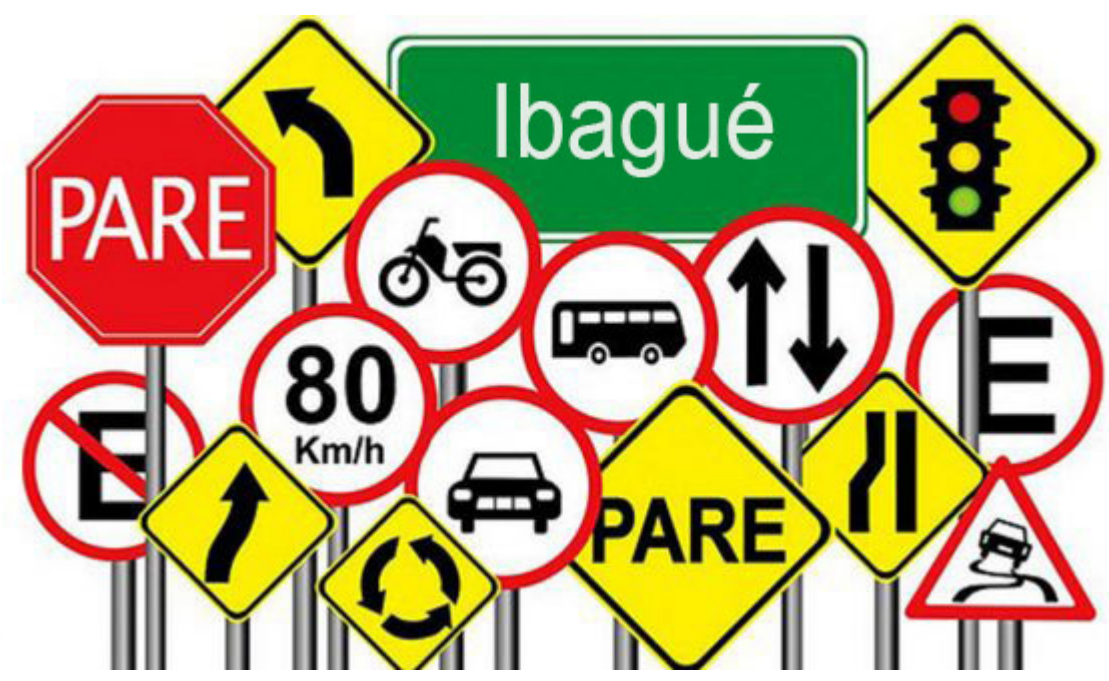

movilidad y ha sido ponente en diferentes eventos, como el Congreso Latinoamericano de Transporte Público y Urbano (CLATPU), el Congreso Colombiano de Transporte y Tránsito (ССTT) y el Congreso Panamericano de Transporte y Logística (PANAM). La revista Indagare tuvo la oportunidad de hablar con él, quién nos comentó su forma de ver la movilidad en la ciudad.

¿Cómo convencer a las grandes compañías de un diseño de calles más inclusivas? Juan Guillermo Zuluaga: Ellas ya se dieron cuenta. Si les llegas a preguntar a los comerciantes de la Carrera Tercera de la ciudad de Ibagué, si quieren que los carros vuelvan a transitar por esa vía, ellos dirán que no. Porque no es lo mismo ir en un carro $\mathrm{y}$ detenerse frente a un centro comercial a estar de pie frente a dicho centro. Inclusive, por la Carrera Quinta, donde hay tanto parqueadero por la vía, preguntas: ¿cuántos de esos carros están comprando en el negocio de al frente de donde están parqueados? Y te sorprenderá que solo uno lo hace, los otros están haciendo algo totalmente diferente.

Las constructoras realmente suplen unos pliegos de condiciones que están dados por las entidades territoriales, que les dan las indicaciones para construir las vías. Pero yo realmente diría que el enfoque que se debe cambiar es aquel que viene del Gobierno, porque son ellos los que dictaminan las políticas públicas y te dicen qué se debe hacer. En algún momento, el hecho de peatonalizar la Carrera Tercera fue primero una decisión política.

Ellos siempre dicen "vamos a mejorar la vía en términos de seguridad”, entonces aquello que hacen es ampliar y volverla segura para los carros. En el momento en el que la construyan, aumentarán las velocidades y será peligrosa para las personas que viven cerca a esa vía. Entonces ¿qué pasa?, siempre se favorece a un solo modo de transporte, el motorizado, dejando de lado a otros, como los peatones. 


\section{¿Cuál es el paradigma que se maneja frente a la movilidad?}

Juan Guillermo Zuluaga: La gente suele creer que el carro es el rey de la vía, y el rey es el peatón. Sí tú vas en un carro, este es una armadura para ti, y te va a mantener relativamente seguro. Si tú te estrellas con una persona, a ti no te va a pasar nada, al carro tal vez un rayón, pero la persona se puede morir.

La gente no se da cuenta de esa vulnerabilidad, pero ¿cómo le digo a una persona que vaya despacio cuando la vía le dice que vaya rápido?, por eso queríamos que nuestro curso de "Diseño de calles para ciudades del siglo XXI" no se centrara en ese diseño de las vías de autopista, sino que realmente se cambiara la mirada tradicional y se pudiese lograr un buen diseño en el que todo sea equitativo para favorecer a los usuarios.

En este mundo tan dinámico e inclusivo, el tema de la movilidad no puede quedarse en la mirada tradicional y mucho menos en el concepto de los futuros profesionales, que serán los encargados de que este principio sea válido en todas sus maneras. Menos mal, la Universidad de Ibagué ofrece espacios de reflexión que nos permiten ampliar el espectro de concepciones, así como lo fue el curso: "Diseño de calles para ciudades del siglo XXI", el que a su vez permitió entender la manera en la que se puede transformar algo tan cotidiano, como las vías, con el fin de garantizar buenas condiciones de vida para todos los ciudadanos.

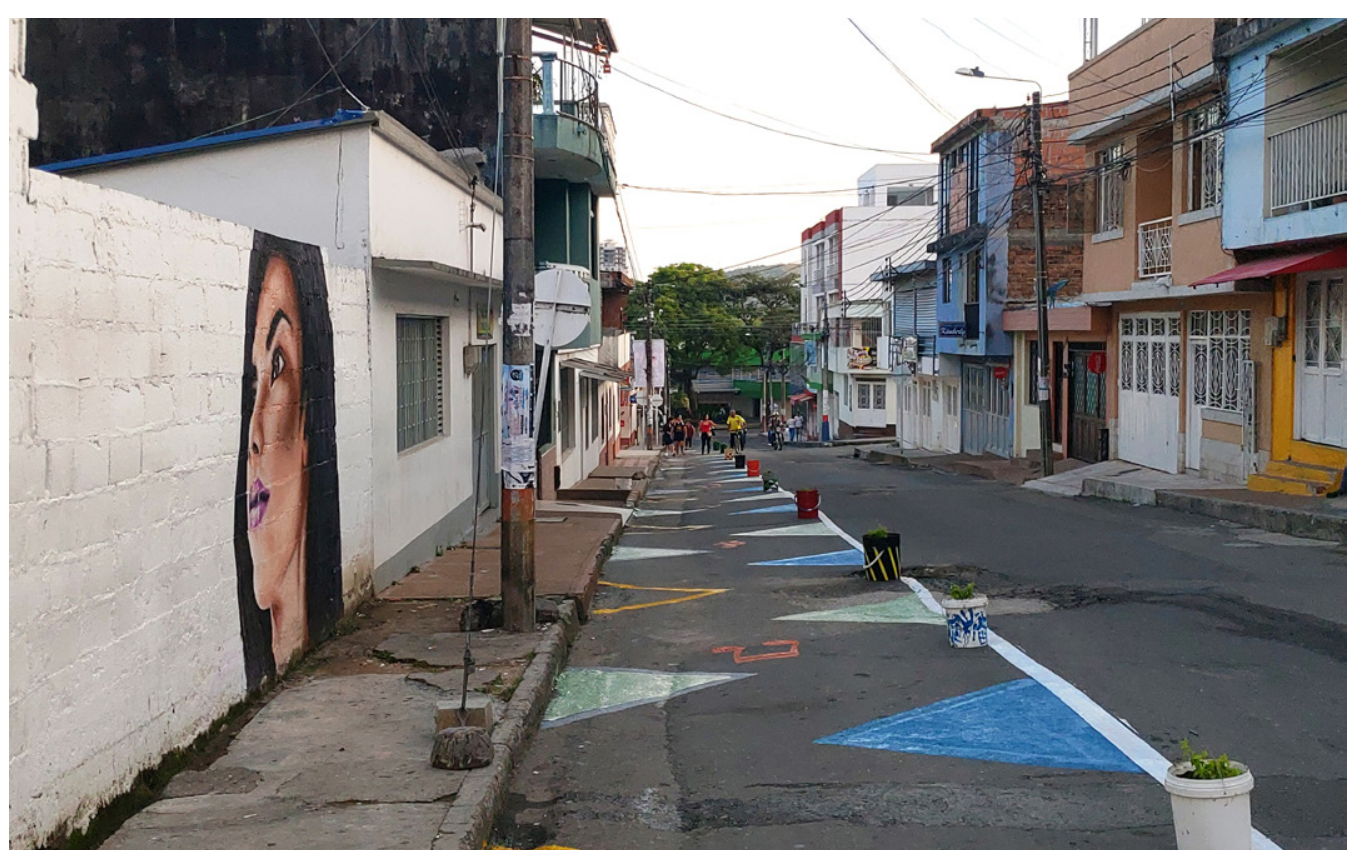

